Positions moyennes des étoiles de comparaison.

\begin{tabular}{|c|c|c|c|}
\hline * & $\alpha 1913.0$ & $\delta 1913.0$ & Autorité \\
\hline I & $10^{h} 43^{m} 3 I^{s} \cdot 46$ & $+13^{\circ} 40^{\prime} \quad 5.5$ & Lpz I 4 I I 7 \\
\hline 2 & 104224.14 & +132925.4 & $\gg \quad 4110$ \\
\hline 3 & I0 $46 \quad 26.22$ & +132833.6 & $\mathrm{Bo} V \mathrm{I}=\mathrm{BD}+\mathrm{I}^{\circ}{ }^{\circ} 30 \mathrm{I}$ \\
\hline 4 & Io $47 \quad 38.44$ & +133339.2 & $\mathrm{Lpz}_{4} \mathrm{I}_{43}$ \\
\hline 5 & I0 $45 \quad 1.73$ & +132324.6 & 4127 \\
\hline 6 & Io 4533.40 & +131612.1 & 4130 \\
\hline
\end{tabular}

Nice, I913 Mai 20.

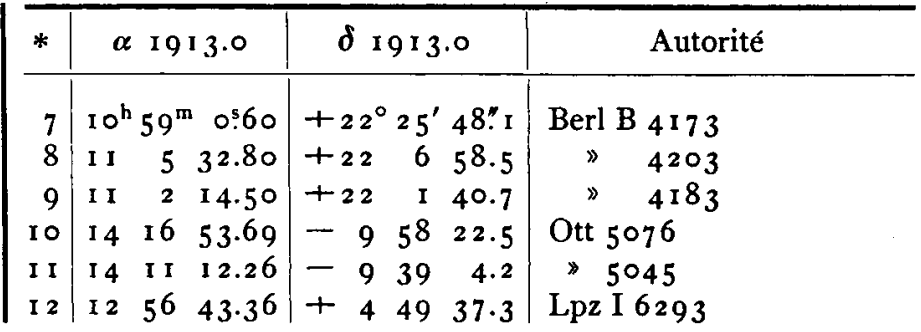

S. Favelle.

\title{
Beobachtungen des Kometen 1913 a (Schaumasse)
}

am $360 \mathrm{~mm}-$ Refraktor der Kopenhagener Sternwarte angestellt.

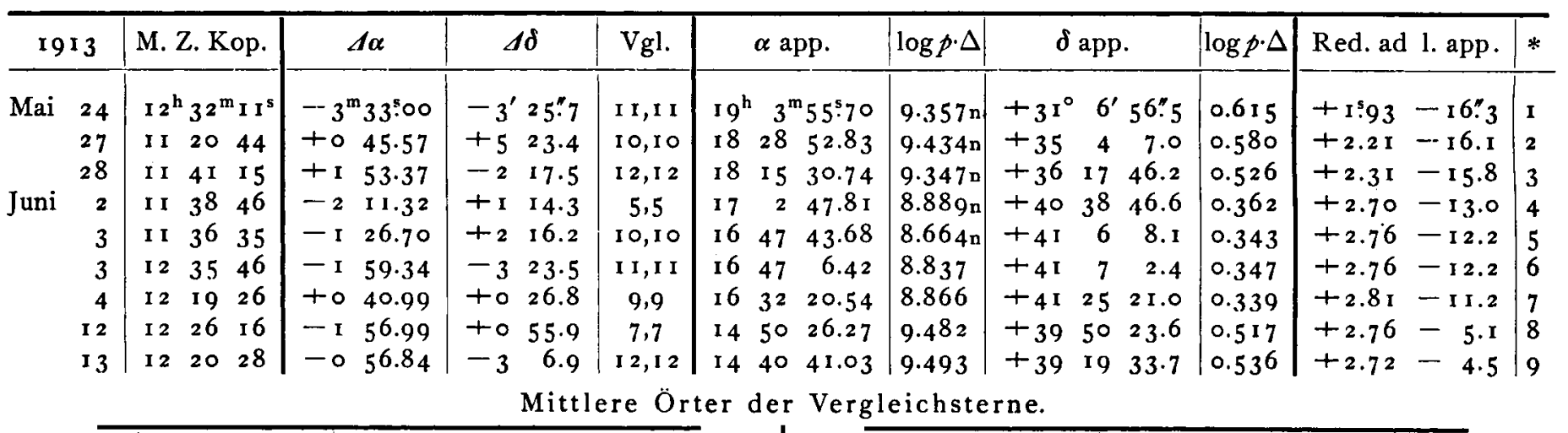

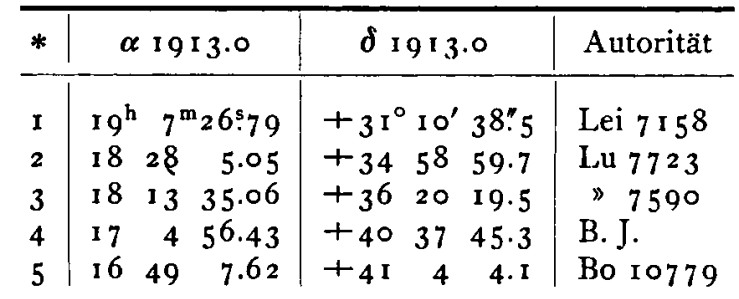

Kopenhagen, Universitäts-Sternwarte, I 9 I 3 Juni.

\begin{tabular}{|c|c|c|c|}
\hline * & $\alpha 1913.0$ & $\delta 1913.0$ & Autorität \\
\hline 6 & $16^{\mathrm{h}} 49^{\mathrm{m}} \quad 3^{\mathrm{s}}: 00$ & $+41^{\circ} \mathrm{IO}^{\prime} 38^{\prime \prime} \mathrm{I}$ & Bo 10778 \\
\hline 7 & 163136.74 & +4125 & $\geqslant 10610$ \\
\hline 8 & $145^{2} 20.5^{\circ}$ & +394932.8 & Lu $626 \mathrm{I}$ \\
\hline 9 & $144 \mathrm{I} 35.15$ & +392245.1 & $\$ 6208$ \\
\hline
\end{tabular}

Ruben Andersen.

\section{Ephemeride für $\alpha$ Canum venaticorum.}

Die Epochen der größten Intensität der dunklen Linie $\lambda=4 \mathrm{I} 2.993 \mu \mu$ im Spektrum von $\alpha$ Canum venat. sind :

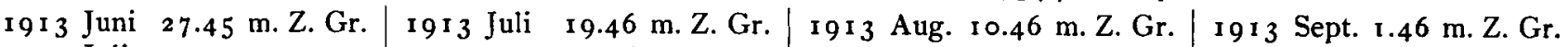

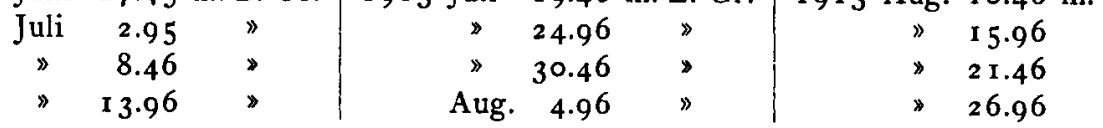

Dauer der Sichtbarkeit etwa 50 Stunden. Periode sehr nahe 5.5० Tage. Andere Linien werden schwach zu diesen Epochen.

Pulkovo, I9I 3 Juni 20.

A. Belopolsky.

Notiz. Die Tätigkeit der Königl. Sternwarte zu Berlin wird am r. Juli im alten Gebäude am Enckeplatz ihren völligen Abschluß finden, und mit diesem Zeitpunkt erfolgt die endgültige Verlegung der Sternwarte nach dem Neubau in Neubabelsberg. Es wird gebeten, von jetzt ab alle für die Sternwarte und ihre Astronomen bestimmte Sendungen mit der neuen Adresse: Königliche Sternwarte, Berlin-Babelsberg versehen zu wollen.

I913 Juni 24.

H. Struve.

Anzeige. Von der "Tafel zur Berechnung der Gibbsschen Ausdrücke, von Norbert Haponowicz " aus Nr. 4653 sind Abzüge auf stärkerem Papier hergestellt, die von der Expedition zum Preise von $0.40 \mathbb{M}$. bezogen werden können.

Inhalt zu Nr. 4664. W. Doberck. Sutton Double Star Observations. 145. - S. Favelle. Observations de petites planètes. I 57. - R. Andersen. Beobachtungen des Kometen 1913 a (Schaumasse). 159. - A. Belopolsky. Ephemeride für $\propto$ Canum venaticorum 159 . Kleine Mitteilungen. 159. 